\title{
Las ideas pedagógicas de Alejandro O. Deustua.
}

\section{UNA LECCION DE JUVEMTUD}

En todo pensador importante y desde luego en todo pensamiento pensado profundamente, hay siempre dos elementos que a menudo se confunden: el contenido de verdades elaboradas con mayor a menor originalidad y perfección técnica, el contingente de pensamientos coordinados y bruñidos por el noble afá⿴\zh11 de brindatos en generosa objetividad, que es lo que se adyierte y seconrovecha, do que se discute y se analiza, lo que nos nueve intelectualmente a la adhesión o al rechazo; y además, una solapada conexión radical con los más entrañables y decisivos estratos del acontecer histórico. Lo primero es abstracto y puro ser, producto de cultura, explicable por referencia a los antecedentes, a las circunstancias dominantes, a las preferencias individuales. Lo segundo es ser concreto, obscuro y misterioso contacto con las fuentes de la vida misma, vibración al unísono con designios irrevocables y apremiantes, afloren o no en la clara conciencia del pensador. El predominio de la abstracta elocubración condiciona el conocimiento y postula sus valores universales y transferibles. El predominio de las disposiciones de sensibilidad y receptividad para el flujo 
vital, condiciona la visión, es decir la capacidad para comprender el sentido, la significación válida para todos los que viven en la nisma dimensión histórica y para inducir a los demás a seguir la misma ruta. Para decirlo en dos palabras, en el primer caso se trata de la vocación científica; en el segundo, de la inspiración. Cuando estas disposiciones se reunen en un espíritu, cuando los dones de la inteligencia se armonizan con la actitud total de una fuerte personalidad, el resultado es la síntesis egregia del pensador que "vive en el mundo", que alienta y promtreve, seduce y atrae, porque revela y traduce intensamente lo que apenas se insinúa en la conciencia adormecida de sus contemporáneos .

A este linaje de espíritu pertenece Alejandro Deustua, en quien armoniza admirablemente la capacidad intelectual con la vocación de maestro, el conocimiento y la erudicción con la emoción humana, la sabiduría con los más depurados sentimientos de amor al Perú. Poco o nada entenderá de la obra deleste maestro jlustre quien se atenga exclusivamente a sus brillantes el inolvidables lecciones de filosofía en la Facultad de Letras de San Marcos, al acervo copioso de sus trabajos sobre axiología, Estética, Historia del Arte, Filosofía de la Educación, a sus innumerables comentarios y versiones de los sistemas filosóficos más importantes de su tiempo, si a la vez no le es dado captar el acento de convicción, la imponente seguridad en el tono afirmativo y rotundo, la valentía para señalar los errores y los defectos nacionales. No conoce ni ha conocido nunca el temor, ni la media voz, ni la endeble vacilación de los tímidos, más peligrosos que los perversos, porque contribuyen sin quererlo y sin saberlo a la desmoralización y al desconcierto dentro de las propias filas. Sus servicios a la cultura, su devoción al espíritu a través de tantos años de vi- 
da intelectual, no han debilitado su vitalidad ni sus sentimientos. A la altura nobilisima de sus noventa años, Detstua se yergue para saludar y aleccionar a sus antiguos alumnos y colegas de la Facultad de Letras, con la misma seguridad emocionante, con la misma energía y resolución con que acostumbraba aleccionar en las aulas sanmarquinas. Nos habla de la educación, de la vida, de la moral, de 1a necesidad de que la enseñanza magistral, en el ambiente propicio de los seminarios, se vuelva eficaz y fecunda. En suma, una lección de optimismo y de juventud.

\section{DETERIMINACION DE SU FILOSOFIA}

Deustua es ante todo un idealista. Aparece en la Universidad en el momento en que las más esclarecidas mentalidades de América rompían lanzas a la vez contra el positivismo y contra el racionalismo. Nos hace pensar en Korn, el eminente maestro argentino. En ambos, casi contemporáneos, se enciendẻẻbnìismo ferver pertlag filosofía, la misma inquietud espiritula fe Anbose estabanepredlestinados para realizar campañas paralelas contra el cerrado y miope positivismo de su tiempo, que atrincherado en una ciencia mediocre y pretenciosa, intentaba acallar dondequiera la voz del espíritu. Hay que pensar lo que sería la cultura de nuestras Universidades hace un poco más de treinta años, cuando Deustua y Prado ennoblecían la enseñanza con su entısiasmo por el saber filosófico y con su decidida vocación de maestros. La juventud, la fe en los grandes ideales, el prestigio de las fórmulas democráticas, una especie de romanticismo espiritualista, con la fuerza de los brotes nuevos y el candor iluminado de la adolescencia, perseguía y fustigaba en sus últimos reductos a los escasos pero tenaces afiliados al positivismo, aferrados a sus posiciones, como los sol- 
dados que siguen combatiendo, porque ignoran la derrota del ejército principal. No es ni puede ser accidental la convergencia de direcciones en la enseñanza, de grandes maestros americanos. Recordamos a Antonio Caso, orientador de las actividades filosóficas en México hasta hace poco. Caso es uno de los más significativos y atrayentes propugnadores del idealismo en América. Tampoco es accidental la ferviente adhesión a la filosofía de Enrique Bergson, en Korn, en Deustua, en Caso. Cuando se haga la historia del pensamiento americano de las últimas décadas, llamará la atención este hecho: la filosofía de Bergson fué recibida no como un sistema, sino como un mensaje. En ninguna parte del mundo se acogió a Bergson con más devoción y entusiasmo que en América. Alejandro Korn expresa su admiración y la honda compenetración con el filósofo francés en ¿su bellísimo libro "La libertad creadora”. Caso vierte su emoción en magistrales discursos y conferencias. Deustua y Prado llevaron el bergsonismo a la Universidad de San Marcos y allí echó proftindas ráices y fforeció en expresiones juveniles "dergaliosa meditación $\mathrm{y}$ " lírico deslumbramiento.

Desde luego, Deustua no fué un bergsoniano unilateral. Su vasto conocimiento de las corrientes filosóficas del tiempo, su vinculación con el neo-kantismo - que fué la filosofía alemana oficial de anteguerra-, a través de los filósofos italianos, su aproximación a Wundt por el costado de la Psicología y su proyección hacia la filosofía de los valores lo defendieron de la adhesión incondicional y el arrobamiento.- Además, hay una dimensión muy importante en el pensamiento de Deustua, que indudablemente concurrió al mismo fin: su moralismo, su inclinación a dirigir y orientar conciencias, su fina sensibilidad para los problemas na- 
cionales que se plantean al pensador. La filosofía bergsoniana careció por mucho tiempo de aplicación a la Etica hasta la aparición de "Las dos fuentes de la moral y de la religión", era teorética pura. El pensamiento de Deustua no podía, pues, encontrar plena satisfacción dentro del bergsonismo. Bajo la fecunda inspiración de Tucken, Deustua se entusiasma con los temas de la Moral y poseído de los más nobles y elevados sentimientos, aplica su sólida cultura al estudio de los problemas morales, educacionales y culturales del Perú, con criterio que sorprende por su claridad y por el valor personal que revela.

Temperamento radicalmente polémico, Deustua no conoce la expresión velada, ni el gesto timorato. Con acento que acusa madurez y virilidad, a la vez que innato señorío, analiza con crudeza los defectos nacionales, el afán de enriquecimiento y de lucro personal, la falta de sentido moral en gobernantes y gobernađos. "Esto explica por qué en todos los negocios públicos en que los bienes económicos juegan un papel considerable, fos que gobiernan carecen de esa libertad ideal, de "sorge voluntad inhibitoria, que impone la resistencia a una coación exterior. Esos negocios se tratan con criterio mercantil individual, que se asocia a una escasísima moralidad." (La Cultura Nacional, pag. 63). Idéntica actitud asume frente al problema del indio, donde encuentran cómodo refugio las pasionsillas y los desahogos apocalípticos de los profesionales de un nacionalismo caduco y resentido, sin más fundamento que el rencor, sin más móvil que el odio y la venganza. Quieren vengar ahora los agravios que los españoles hicieron a los indios hace más de trescientos años. Con to cual no hacen sino ahondar la división que ya hizo a su tiempo la historia y que todavía mantiene la geografía. Según Deustua, la esclavitud de la conciencia en el 
indio es irremediable y el Perú: "debe su desgracia a esa raza indígena que ha llegado en su disolución psíquica a obtener la rigidez biológica de los seres que han cerrado definitivamente el ciclo de su evolución y que no ha podido trasmitir al mestizaje las virtudes propias de razas en el período de su progreso".

Una limitación se advierte en el pensamiento de Deustua, explicable en función de su tiempo y paradójicamente en función de su lucha contra el positivismo: su falta de sentimiento metafísico. Ello es el tributo natural que tiene que pagar al adversario. Cuando se pelea de verdad, es porque tuno se siente en, el mismo plano que el enemigo a quien se le disputa el campo. Lo salva, sin embargo, su concepción de los valores, su intensa emoción moral, su calurosa exégesis de la libertad. Lo que pierde en hondura y afincamiento lo gana en elevación y en fuerza convincente. Si algo conmueve en el pensamiento de Deustua es el marcado contraste entre la realidad mezquina de los apetitos y la lim-

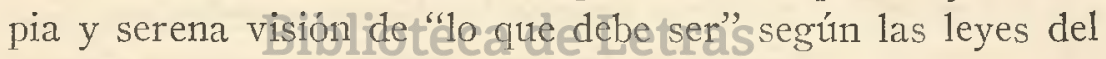
espíritu y la libertad.pDesde luegon falta „de sentimiento metafísico no es lo mismo que falta de metafísica. Deustua lo comprende así y lo expresa repetidas veces, sobre todo cuando trata de fundamentar filosóficamente la educación.

\section{PEDAGOGIA Y FILOSOFIA}

Si intentamos tuna génesis del pensamiento pedagógico de Deustua, tenemos que partir del mismo punto que hemos escogido para obtener una visión de su filosofía. Su lucha contra el positivismo y el racionalismo. No podía, pues, bastarle una elaboración conceptual abstracta ni una mera técnica de la educación. Un espiritu superior, fuertemente influenciado por la filosofía de su tiempo, y a la vez dotado 


\section{$-{ }_{167-}$}

de fina sensibilidad para captar la vibración de los problemas reales que se plantean en todos los órdenes al Perú, tenía que considerar insuficiente la pura ideología lo mismo que los procedimientos que propone la experiencia científica positiva, sin ideal, sin dirección, sin espíritu. Así Deustua se preocupa por encontrar "en un nuevo idealismo sintético y positivo, soluciones acordes con los progresos de la ciencia de la naturaleza física". No proclama un idealismo vacío, ni se siente adversario de las ciencias de la naturaleza, ni rehusa por consiguiente la colaboración de los hombres de ciencia. Su idealismo es, como él dice, sintético o en todo caso se dirige a una mejor interpretación de la realidad, no a su falsificación. No desconoce la legitimidad de la experiencia, pero propugna la necesidad de colocarse en un plano de realidad superior, en el que entren, como componentes los fenómenos de la experiencia objetiva y los de la subjetiva.

Con auténtica inquietud y fervor por las nuevas ideas, Deustua proclamaba la necesidad de que la Filosofía se pusiera en armonia con el espiritu contemporáneo; con el objeto de encontrar organos superiores de acción y de vida, en los que se reduzcan o se atenúen los conflictos existentes, y la libertad individual pueda adquirir una mayor expansión, favoreciendo el progreso social. Nada más claro y expresivo que estas palabras para apreciar el sentido práctico de su filosofía, su afán por esclarecer los problemas actuales, su permanente y fundamental actitud de pensador que ama lo concreto y que busca en la realidad y en la vida los más nobles estímulos para la especulación. Si in-tentáramos reducir su pensamiento a una fórmula simple, podríamos escoger la siguiente: el pensamiento no es un fin en sí mismo: lo que justifica la filosofía es el servirnos de medio para promover y realizar los más altos valores 
humanos: la libertad, la solidaridad y en último término la felicidad. En el fondo, el pensamiento de Deustua tiene un profundo sentido clásico; resuena en él, armoniosamente, con vivo acento de humanidad, la preocupación por la vida como totalidad, como unidad de conocimiento y praxis, la preocupación por la felicidad individual y social.

Para Deustua, la Pedagogía no es una disciplina autónoma; ni puede serlo, porque ella no puede señalar por sí misma su finalidad. Tampoco dispone de los medios necesarios para llevar a cabo su labor. La conciencia de su finalidad sólo se esclarece en el campo de la filosofía; y sus elementos empíricos y los medios que necesita para realizar sus fines tiene que tomarlos de la Psicología, de la Sociología, etc. La Pedagogía, es, pues, ciencia aplicada, que aprovecha los conocimientos de otras ciencias y les dá una dirección particular. Esa dirección la toma indudablemente de la filosofía. Ya pasó la época en que la Pedagogía se reducía a un conjunto de reglas empíricas para adiestrar al educando y trasmitirle determinados conocimientos. Ni es tampoco posible hacer Pedagogía a base de Filosofía y Psicologia, como si el ser humano no hubiera superado todavía el nivel de la naturaleza. La Pedagogía es hoy Filosofía de la Educación. No en el sentido de reglas generales o principios universales de la educación, deducidos de las observaciones empíricas ni como conclusiones sacadas de una determinación apriori de la naturaleza humana. La Peda-gogía considerada como Filosofía de la Educación entraña el problema del "destino del hombre en el seno del mundo, su verdadera felicidad en relación con las leyes que la economía, la política, la moral, el arte, la religión han estableciclo o pretenden establecer en la sociedad contemporánea". "Por consiguiente - según las ideas de Deustua- no es ni puede ser ajeno a la educación ningún dato de la experien- 
cia, puesto que ella considera al hombre en el seno del mundo", sobre todo, si esa experiencia ha sido controlada por métodos científicos. Nadie puede oponerse a que se determinen científicamente las leyes de la fatiga mental, o las de la memoria, o las de la emoción. Lo inadmisible es que se pretenda circunscribir el problema de la educación a términos de investigación empírica, sin fe, sin ideales, sin espíritu, y lo que es peor, sin elementos ni garantías de que tal investigación se ha realizado en condiciones científicamente satisfactorias. Un ejemplo lo tenemos en la pretendida dirección psicologista, que educa al niño con el mismo criterio con que se adiestra a un animal. Una variante del psicologismo es el llamado paidocentrismo, en el que se refugia la ignorancia y la mediocridad de los profesionales de la pedagogía de escuela priniaria.

Tampoco es viable hoy una Pedagogía suspendida por unos cuantos prejuicios racionalistas o religiosos. Tal vez sea necesario que la experiencia misma nos demuestre una vez más - ya lo demostró a su tiempo, pues los males de hoy son el producto del muestrascescuelas ytdel fas doctrinas que las alentaron-querningunairedagogía plede fundarse sólidamente sobre otras bases que un profundo y completo conocimiento de la naturaleza humana por una parte, y por otra una amplia concepción de la cultura. Naturaleza humana y cultura son así los dos polos materiales entre los que se desarrolla toda actividad pedagógica. La Etica y la Filosofía serían los dos polos formales. No se hable pues, de pedagogía autónoma, ni de pedagogos técnicos. Porque la técnica en la pedagogía es lo menos importante. Es lo que se aprende en poco tiempo. La metodología, los procedimientos, la manera de interpretar un plan de estudios. En cambio, hay algo que se aprende con dificultad. Es el contenido mismo de lo que se enseña, la orientación, la 
inspiración y el alma que se pone en lo que se dice. Enseñar — sin que con esto se niegue la importancia de los conocimientos técnicos en pedagogía - es actividad natural en las almas egregias, irradiación de la personalidad. Así se explica que no haya existido una sola de estas almas que no haya tenido discípulos, aunque no haya estudiado pedagogía en, ninguna escuela. Y para ello están demás los prejuicios racionalistas y religiosos, que a su modo constituyen también una técnica, porque a la vez que fines son medios, en nuestro concepto inapropiados, para despertar en el educando la conciencia de una perfección que se puede alcanzar.

Comprendo que me expongo con estas palabras a la censura de quienes propician una orientación religiosa en la enseñanza. Creo-que en este sentido lo que conviene es más bien, disponer al educando por todos los medios posibles a comprender y sentir los valores religiosos y la presencia de Dios en el Úniverso; que oprimir su espontaneidad imponiéndole conceptos hechos $\mathrm{y}$ nociones inteligibles sólo por los aduitos, cuya significacion éstos pueden captar porque a ello los induce la vidanyersona y sus graves problemas. La mentalidad de los niños es particularmente sensible a los valores religiosos a condición de que éstos se manifiestan envueltos en el cendal de la fantasía. El mundo del niño es mágico y artístico, no teorético ni científico. Es un mundo hecho de gracia y de belleza sensible, de temor y de honda sensibilidad para el misterio. El verdadero educador comprende y aprovecha estas determinaciones del alma infantil para la obra trascendental de revelarle los aspectos de la cultura que le son accesibles y en la forma técnica más apropiada.

Psicologismo empirista y racionalismo a priori, son direcciones unilaterales, que no pueden ofrecer lo que la 
Pedagogía de este tiempo necesita, es decir, visión central y total de los problemas humanos, aptitud para la valuación correcta, noción clara y exacta del ideal de perfección que determina el fin del proceso educativo. Lo primero se obtiene por la Filosofía. Las ciencias particulares, de la naturaleza o del espíritu, presentan aspectos parciales de la realidad humana. La Filosofía en cambio tiene el sumo privilegio de ahondar en la vida del hombre, considerándolo en todo momento como una totalidad, como un ente que se encuentra en el Universo y cuya significación se descubre únicamente cuando se le estudia en su plena integridad. La valuación correcta supone corrección en la actitud valorativa. Así como una postura forzada o unos ojos defectuosos alteran y descomponen, los objetos de la percepción sensible, la actitud moral incorrecta, la pasión política o el interés personal y sobre todo el resentimiento, contribuyen a falsear la visión correcta y natural del mundo de los valores. En cuanto al ideal de la Educación, Deustua exige uno que sea forma viviente de posible realizacion y que responda a un orden nuevo en el cuat los terribles dilemas planteados por la tradición se conviertan en líneas convergentes. Vale decir, conciliación y síntesis fecunda. Integración y no descomposición y exclusivismo. Afirmación de los valores y no menguada negación. Así y no en otra forma es posible vivir la emoción de la vida actual, emoción de máxima comprensión y de máxima felicidad. La Filosofía y la vida misma - dice el Maestro-- pretenden sustituir las formas simplistas por otras sintéticas, que no produzcan la disgregación del complexo humano, sino que comprendan todos los elementos que lo constituyen, para establecer una armonía evolutiva en que la libertad sea función de una libertad espiritual superior al hombre individual y que rea- 
liza fines de moralidad absolutos, fuera de los cuales no existe la felicidad estable y duradera .

Así llegamos al núcleo del pensamiento pedagógico de Deustua. Esto es lo más significativo en él: su moralismo, clave de su filosofía y de sus más profundas ideas. "Cuantos hayan meditado con alguna atención sobre el problema pedagógico, habrán comprendido que su solución depende de la que se dé al problema moral. El criterio para distinguir lo bueno de lo malo debe estar formado ya, antes de saber cómo deben disciplinarse las energías humanas para realizar lo que se cree bueno y rechazar lo que se considera como malo." La pedagogía requiere, pues, una previa justificación, es decir, una teoría de la conducta humana, de sus principios, de sus fines; y desde luego, como los fines de la conducta del hombre se encuentran en relación con los valores de la vida, del universo, de la cultura, como los fines que el hombre se propone tienen que armonizarse con los fines colectivos, la cuestión moral a su vez reclama la solución de otras Cuiestionescde mayoe alcance. De este modo el pensamientorde PDeustua, cdncidiendo fuertemente en el campo de la pedagogía, se interna poco a poco, por sucesivos efectos de armonía y resonancia en temas cada vez más interesantes y atrayentes.

Todas las disertaciones de Deustua, sobre la moral, giran alrededor de tres conceptos fundamentales: libertad, armonía, felicidad.

El principio de libertad representa algo fundamental en su sistema, la base y al mismo tiempo la suprema aspiración. Es sumo principio de dignidad; por eso se le profesa una veneración casi religiosa. Representa el valor del individuo, que se afirma rotundamente sobre el orden social, que reclama sus derechos a la autonomía frente a un mundo que siente hostil y con el cual no le agrada entablar 
relaciones. Desde el punto de vista cultural, representa la aspiración del hombre moderno, del burgués individualista que emerge por debajo de los escombros medioevales, y que después de tres siglos acaba por plasmarse en fórmulas filosóficas y políticas en Rousseau y la Revolución, Francesa. La libertad ha sido no sólo principio de autonomía, sino también bandera de rebeldía. Lo mismo la Moral que la Pedagogía de Deustua reclaman el principio de la libertad como fundamental. Es verdad que, según Deustua, la libertad debe conciliarse con el orden. Lo único que no se explica es cómo puede realizarse la conciliación entre principios absolutos, sin que ninguno de los dos resulte sacrificado. Cuál sería la forma de conciliar la libertad con el orden en el siguiente caso: el Estado me manda que pague los impuestos, pero mi libertad exige no pagarlos. Se paga o no se paga, y se sufren, las consecuencias. No conozco los términos medios. Lo mismo ocurre en todas las formas de la vida jurídica, económica, familiar. Otro ejemplo: los padres están obligados̊lal alimentarla șusthijos, porque así lo establece la moral lo prescribelietoderecho. Este deber lo cumplen casi todos los padres espontáneamente. Se quisiera saber la forma de conciliar el orden con la libertad en caso del padre que haciendo uso de su autonomía personal, se niega a dar alimentos a su hijo. Ahora busquemos un ejemplo en el dominio de los llamados valores sociales individuales, es decir, en el campo de aquellos valores sociales que se cumplen sin la intervención del Estado. Me refiero a la caridad, en cuyo dominio desaparece toda coacción de parte de la sociedad y del Estado. Si se trata de un auxilio que se nos solicita, por persona que se encuentra en verdadera necesidad (no es preciso que sea dinero lo que se nos pide), nos encontramos ante el mismo dilema que en los ejemplos anteriores; prestamos o no prestamos el auxilio. 
Si lo prestanos, nos sometemos al orden objetivo; si no lo prestamos, afirmamos nuestra libertad. En ninguno de los dos casos se ve conciliación del orden con la libertad. Uno de los dos tiene que perecer para que triunfe el otro. Y precisamente la sociedad formula juicios morales positivos cuando, en situaciones como esta última, triunfa el orden objet:vo, es decir, cuando se realiza la acción benéfica. Una mente sutil pensará que la conciliación se hace posible cuando se presta el auxilio de buena gana. A esta mente se le puede contestar que en ese caso cabría sostener lógicamente que los esclavos son libres, porque llevan sus cadenas de buena gana.

Estas y otras reflexiones que omitimos aquí refuerzan nuestra convicción de que el orden y la libertad no son dos enemigos que se ponen de acuerdo; y desde luego que la libertad no es ningún principio formal ni tampoco final. Si fuera formal, sería vacío; si fuera final, habría que sacrificarle todo. Al contrario, la libertad es mera condición

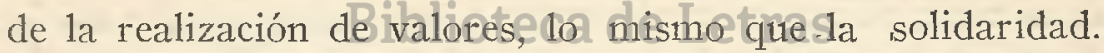
La solidaridad entroitodosidosepefuanos,spor ejemplo, es buena, porque es la condición indispensable para realizar infinitos y elevados valores individuales y sociales. La ciencia, el arte, la técnica, las formas de la vida social, las más altas virtudes como el heró́smo por la patria se promueven bajo el estímulo de la solidaridad nacional. Igual cosa ocurre con la libertad, que expresa la espontaneidad del espíritu para la realización de los valores: arte, religión, ciencia, pedagogía, técnica, se realizan gracias a la espontaneidad del espíritu que se supera constantemente en la vida ética en, su eterna empresa de preferir los valores más elevados a los más bajos.

E1 principio de armonía desempeña importantísima función en la moral de Deustua. Traduce un sentimiento 
de simetría y de belleza. En, la pedagogía, Deustua se refiere a la necesidad de desarrollar armónicamente todas las capacidades, incluso la capacidad física. Su pensamiento tiene en este punto inequívocas resonancias de platonismo y esteticismo. En moral, debe entenderse por armonía la conciliación del orden con la libertad, a que nos hemos referido y por lo tanto a la eliminación de todos los posibles conflictos. Si ello fuera posible, indudablemente que sería muy hermoso. Desgraciadamente, la vida nos enseña a diario que las actitudes morales entrañan conflictos casi siempre insolubles. Un solo hombre que se propusiera ser bueno, veraz, justo, valiente, generoso, en poco tiempo llegaría a producir los más graves trastornos y conflictos colectivos. Si desaparece esta noción de conflicto en la vida ética, pierde ésta uno de sus más eficaces estímulos.

Corolario del principio de armonía es la felicidad, vale decir, el goce, porque no es admisible sostener que hay felicidad en el ascetismiós si ta hubierd, segía de una especie muy particular, Jennsistiríanenlitoocontrario de to que se entiende comunmente por felicidad. Consistiría en no tener, en no gozar, en negarse constantemente. La Felicidad es, a la inversa, tener, gozar y afirmarse constantemente. En este punto no se puede estar en desacuerdo con Deustua. Revela sin duda fina perspicacia filosófica y noble naturaleza. Pero debe advertirse que los goces constitutivos de la felicidad, mejor dicho el gozo, y mejor todavía la dicha, no consiste en poseer y en afirmar una especie determinada de bienes; cualquiera y todos los bienes a la vez pueden ser afirmados, siempre que se les someta a las leyes de la preferencia y la jerarquía. En ninguna forma se puede admitir como goce exclusivo el goce sensible y menos aún el utilitario o material, el cual implica en realidad 
un verdadero ascetismo (véase "E1 Resentimiento en la Moral", de Max Scheler).

Para terminar este apartado, es preciso hacer alusión al intenso y permanente repudio que hace el profesor Deustu del valor económico. Esta severa actitud de repudio se explica claramente si se considera que Deustua combate las pretensiones ilegítimas de la valuación económica y la sumisión de todos los órdenes al económico, y por consecuencia del envilecimiento de todos los valores, incluso los más elevados, sometidos a la estimación de los comerciantes, con daño evidente para la cultura. Pero Deustua no desconoce la verdadera importancia de los fenómenos económicos, siempre que seles asigne una órbita y se les mantenga en ella. Lo que Deustua condena es la tiranía de lo económico. De su libro "La Cultura Nacional" entresacamos lo siguiente: "Ninguna tiranía es más desastrosa e inmoral, que la derivada de la disciplina económica. El individualismo cuentabconj las simpatías del mundo, que convierte en un ídolo al becerro de oro y alimenta la corrupción y el servilismo, generadores de toda tiranía. La riqueza, como único valor humano, se impone a los que obedecen como a los que dirigen, dividiendo a la sociedad, no en hombres buenos y malos, sino en ricos y pobres. La seducción, de los goces que promete la riqueza, disciplina las huestes humanas y las dispone para la guerra en su ambición de monopolizar esos goces, tanto materiales como espirituales. La disciplina económica va hasta erigir el materialismo histórico en la única filosofía positiva, en la única moral y hasta en la única religión. De esa fuente desprende todos los acontecimientos individuales y sociales y crea una nueva Biblia, dentro de la cual se sumergen religión, arte, derecho, política y lógica. El espectáculo desastroso 
un verdadero ascetismo (véase "El Resentimiento en la Mora1", de Max Scheler).

Para terminar este apartado, es preciso hacer alusión al intenso y permanente repudio que hace el profesor Deustu del valor económico. Esta severa actitud de repudio se explica claramente si se considera que Deustua combate las pretensiones ilegítimas de la valuación económica y la sumisión de todos los órdenes al económico, y por consecuencia del envilecimiento de todos los valores, incluso los más elevados, sometidos a la estimación de los comerciantes, con daño evidente para la cultura. Pero Deustua no desconoce la verdadera importancia de los fenómenos económicos, siempre que seles asigne una órbita y se les mantenga en ella. Lo que Deustua condena es la tiranía de lo económico. De su libro "La Cultura Nacional" entresacamos lo siguiente: "Ninguna tiranía es más desastrosa e inmoral, que la derivada de la disciplina económica. El individualismo cuentabcon lilas esimpatías del mundo, que con-

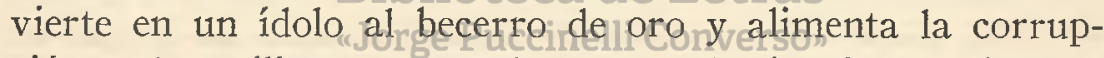
ción y el servilismo, generadores de toda tiranía. La riqueza, como único valor humano, se impone a los que obedecen como a los que dirigen, dividiendo a la sociedad, no en hombres buenos y malos, sino en ricos y pobres. La seducción, de los goces que promete la riqueza, disciplina las huestes humanas y las dispone para la guerra en su ambición de monopolizar esos goces, tanto materiales como espirituales. La disciplina económica va hasta erigir el materialismo histórico en la única filosofía positiva, en la única moral y hasta en la única religión. De esa fuente desprende todos los acontecimientos individuales y sociales y crea una nueva Biblia, dentro de la cual se sumergen religión, arte, derecho, política y lógica. El espectáculo desastroso 
que ofrece la humanidad en estos momentos es obra de la tiranía económica”.

\section{LA EDUCACION Y LA UNIVERSIDAD}

El problema de la Universidad tiene dos aspectos: la Universidad debe tener una estructura que responda a los fines para los cuales ha sido creada. Es esto lo primero y lo fundamental. Lo otro es la misión social que debe cumplir. Deustua, como pocos, ha visto claro este asunto. La Universidad es el más noble y elevado instrumento de cultura. Por lo tanto su constitución debe responder con eficiencia a sus fines. Por eso la Universidad está integrada por $\mathrm{Fa}^{-}$ cultades, que proporcionan cultura intelectual en los diversos ramos del saber. Pero además la Universidad tiene una función educadora que "abarca las energías físicas, biológicas, intelectuales, volitivas y sentimentales. En el gimnasio el cuerpo educa sus energías, conquistando la libertad de sus movimientos y la salud de sus miembros. En el seminario adquiere por el trabajo personal, el criterio clentífico, histórico, filosófico, juridico, politica y económico, que la simple repetición de las ideas no puede ofrecerle. En la clínica, el gabinete y el laboratorio consigue llevar con acierto a la práctica lo que la simple teoría no puede ofrecerle".

Tal estructura, es ciertamente la más adecuada y eficiente para cumplir los más elevados fines universitarios y la que más conviene para realizar la misión social propia de la Universidad. Esa misión es, según Deustua, esencialmente moral, porque a la Universidad le está encomendado el educar con la palabra y con el ejemplo. Pero el fin específico que la Universidad se propone es "educar a nuestra clase dirigente, infundiéndole sentimientos de jus- 
ticia, de sinceridad, de firmeza, de tolerancia, de amor a la verdad, de independencia y dignidad para considerar a los demás hombres, no como medios destinados a satisfacer fines egoístas, sino como fines creados para una armonía superior".

En suma, la Universidad debe educar, además de instruir; porque los hombres educados por la Universidad son los futuros educadores. No sólo educa el profesor graduado. También educa el profesional honorable, el magistrado que no cotiza sus fallos, el militar que combate por la Patria, el sacerdote que se consagra a su ministerio, el político que promueve y defiende los intereses de la colectividad. Este tipo de hombres es el que hay que formar, porque no se puede importar del extranjero. Los técnicos pueden ser importados. "Lo que el Estado no puede hacer es traer del extranjero a los hombres patriotas y de elevada moralidad, que se consagren a las funciones políticas propias del gobierno nacional. No se pueden contratar hombres que formen eBcuerpot judicial $\mathrm{y}$ legislativo. Ministros de Estado y Diplomáticos uc prefectos, sustb-prefectos y gobernadores, jefes de los departamentos de administración, todo ese inmenso organismo del que depende la felicidad nacional. El principal interés del Estado se encuentra en la constitución de ese organismo, abandonado entre nosotros al vaivén de los agitadores políticos que conspiran contra él."

EnRIQUe Barboza 